\title{
Combined rock slope stability and shallow landslide susceptibility assessment of the Jasmund cliff area (Rügen Island, Germany)
}

\author{
A. Günther ${ }^{1}$ and C. Thiel ${ }^{2, *}$ \\ ${ }^{1}$ Federal Institute for Geosciences and Natural Resources, Hannover, Germany \\ ${ }^{2}$ Institute for Geography, University of Tübingen, Tübingen, Germany \\ *now at: Leibniz Institute for Applied Geophysics, Hannover, Germany
}

Received: 4 November 2008 - Revised: 30 April 2009 - Accepted: 30 April 2009 - Published: 8 May 2009

\begin{abstract}
In this contribution we evaluated both the structurally-controlled failure susceptibility of the fractured Cretaceous chalk rocks and the topographically-controlled shallow landslide susceptibility of the overlying glacial sediments for the Jasmund cliff area on Rügen Island, Germany. We employed a combined methodology involving spatially distributed kinematical rock slope failure testing with tectonic fabric data, and both physically- and inventory-based shallow landslide susceptibility analysis. The rock slope failure susceptibility model identifies areas of recent cliff collapses, confirming its value in predicting the locations of future failures. The model reveals that toppling is the most important failure type in the Cretaceous chalk rocks of the area. The shallow landslide susceptibility analysis involves a physically-based slope stability evaluation which utilizes material strength and hydraulic conductivity data, and a bivariate landslide susceptibility analysis exploiting landslide inventory data and thematic information on ground conditioning factors. Both models show reasonable success rates when evaluated with the available inventory data, and an attempt was made to combine the individual models to prepare a map displaying both terrain instability and landslide susceptibility. This combination highlights unstable cliff portions lacking discrete landslide areas as well as cliff sections highly affected by past landslide events. Through a spatial integration of the rock slope failure susceptibility model with the combined shallow landslide assessment we produced a comprehensive landslide susceptibility map for the Jasmund cliff area.
\end{abstract}

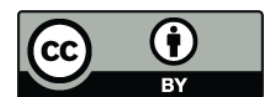

Correspondence to: A. Günther (a.guenther@bgr.de)

\section{Introduction}

The famous Jasmund cliff of Rügen Island (Germany) is composed of soft, intensely fractured, Cretaceous chalk rocks that are in many parts pseudo-concordantly overlain by Pleistocene glacial deposits consisting of till, clay, and sand (Fig. 1). Both stratigraphic successions have undergone strong subglacial deformations in the Late Quaternary, resulting in tight folding and shearing of the Pleistocene deposits, and thrusting accompanied by more open folding of the Cretaceous chalkstones. The entire lithostratigraphic sequence was uplifted and segmented into thrust-bounded structural complexes during the last glacial (Steinich, 1972) and subsequently capped and discordantly overlain by the youngest glacial sediments. The Cretaceous rocks now form a steep cliff more than $100 \mathrm{~m}$ in height that is subdivided by gentler dipping slope sections where Pleistocene deposits predominate.

Since the last glacial period, the Jasmund cliff has been subject to gravitational mass movements. The stability of the soft Cretaceous chalk is chiefly controlled by the orientation and the conditional properties of pre-existing geological discontinuities (joints, bedding planes), while the sliding susceptibility of the Pleistocene sediments is governed by their structural position, geomorphological setting and material composition (e.g. Hutchinson, 2002; Duperret et al., 2004; Obst and Schütze, 2006). In Jasmund, large-volume cliff failures comprise complex rock falls of the Cretaceous chalk along water-saturated discontinuity planes during or after periods of high precipitation. In many cases, Pleistocene glacial sediments, composed of impermeable tills and permeable sands, are also involved when the Cretaceous chalk collapses (Fig. 1). Because the chalk is a considerably soft material with high porosity, the rock fall materials (when saturated) are subject to intense dissolution and fragmentation processes and are rapidly transformed into chalk flows (e.g. Hutchinson, 2002; Williams et al., 2004; Obst and Schütze,

Published by Copernicus Publications on behalf of the European Geosciences Union. 


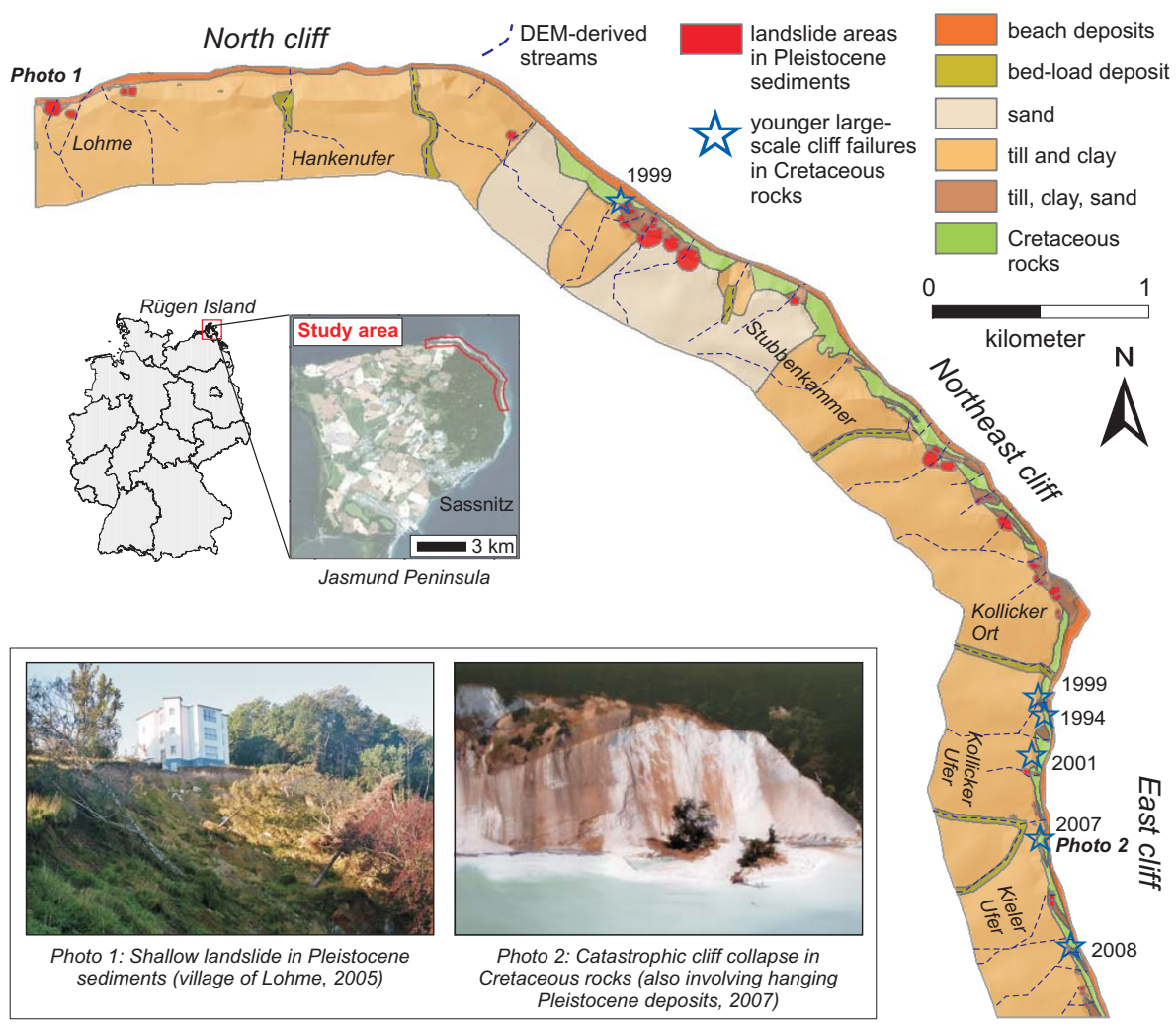

Fig. 1. Geological map of the study area with landslide distribution in Pleistocene sediments and locations of younger large-volume cliff failures in Cretaceous rocks (with year of occurrence, compiled by Lange, 2007).

2006). Recently, the interest of the coastal cliff stability significantly increased due to spectacular large-volume cliff failures and landslides that occurred over the last few years (Fig. 1).

In our study area, the Jasmund cliff can be subdivided into three sections (Fig. 1): (i) a E-W oriented north section with a low topographic gradient and well-developed beach deposits at the cliff toe, (ii) a NW-SE striking northeast section reaching the highest elevations, and (iii) a N-S oriented east section with a significant concave cliff profile. Cretaceous rocks crop out over large areas along the east and the northeast cliff sections, whereas only one approx. $200 \mathrm{~m}$ long outcrop exists along the north cliff. Large dormant and active landslides in Pleistocene sediments are abundant along the northeast cliff, whereas along the east cliff they are frequent but smaller in size. Along the north cliff, landslides in Pleistocene sediments are only present in the vicinity of the village Lohme (Fig. 1).

In this paper, we present a combined approach to generate an integrated failure susceptibility map for the Jasmund cliff taking into account both the sliding susceptibility of the Pleistocene glacial sediments and the slope stability of the Cretaceous rocks (Fig. 1) . First, we describe the data and the methodology used to assess the structurally-controlled cliff failure susceptibility using a spatially distributed ap- proach. Then, we outline and discuss the procedures we used to evaluate the topographically-controlled shallow landslide susceptibility. We then present a combined failure susceptibility map attributed both to the structurally-controlled complex failures in the Cretaceous chalk cliff sections and to the shallow landslides in the Pleistocene glacial deposits. Finally, a discussion on further work to investigate the landslide susceptibility of complex cliff terrains in more detail is provided.

\section{Rock slope failure susceptibility evaluation}

\subsection{Data}

We assessed the failure susceptibility of the Cretaceous chalk cliff portions by performing spatially distributed kinematical rock slope failure testing on geological discontinuities with the SLOPEMAP software of the RSS-GIS package (Günther, 2003; Günther et al., 2004). The database for the kinematical rock slope failure testing procedures consists of a $5 \times 5 \mathrm{~m}$ digital elevation model (DEM) provided by StAUN (Staatliches Amt für Umwelt und Natur, Rostock, Germany), more than 1500 directional measurements of individual planar discontinuities, and a detailed cliff mapping prepared by Steinich 


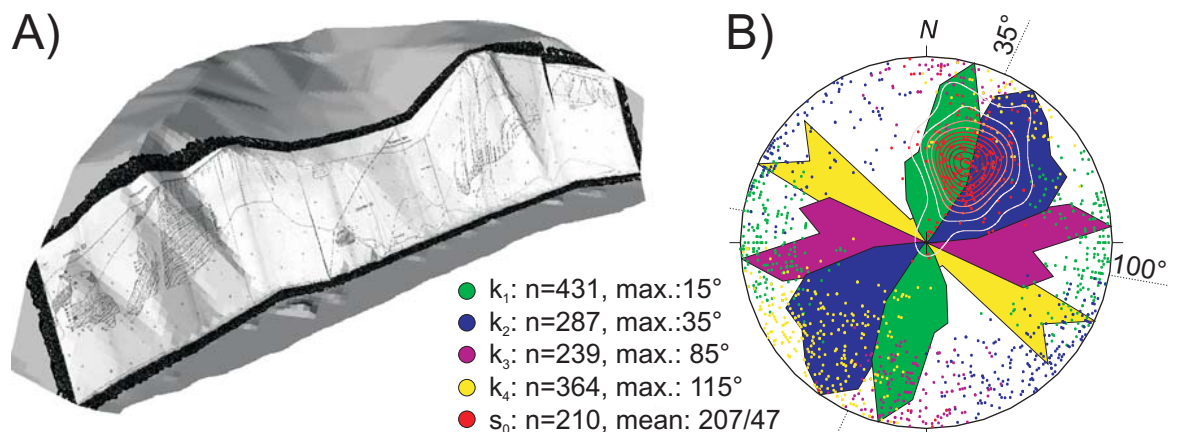

Fig. 2. (A) DEM-draped, georeferenced cliff mapping of Steinich (1972, detail). (B) Synoptic tectonic fabric diagram (equal area projection, lower hemisphere). The strike direction roses for the joint sets $k_{1}-k_{4}$ were computed with an interval of $10^{\circ}$, the contour lines for the bedding planes $\left(\mathrm{s}_{0}\right)$ were obtained with a density interval of $5 \mathrm{n}$.

(1972; Fig. 2). Additionally, we carried out rock mass rating (RMR; Bieniawski, 1989) procedures at four representative observation sites to estimate the shear strength of the discontinuities as determined by their residual friction angle.

The synoptic tectonic fabric diagram shown in Fig. 2 displays four joint sets in the Cretaceous rocks $\left(k_{1}, k_{2}, k_{3}, k_{4}\right)$ that can be clearly distinguished at each observation site. They significantly vary in orientation throughout the surveyed cliff sections, and consist of two conjugated fabric sets with conjugation planes striking WNW $\left(35^{\circ}\right.$ for $\left.k_{1} / k_{2}\right)$ and ESE $\left(100^{\circ}\right.$ for $\left.k_{3} / k_{4}\right)$, respectively (Fig. 2). The mean plane of the sedimentary bedding data $\left(\mathrm{s}_{0}\right.$, Fig. 2) moderately dips SW. However, due to the intense deformation of the Cretaceous sequence, bedding plane orientations also vary with respect to the structural position of the chalk rocks in each thrust complex.

Based on DEM data, ortho-photographs, and GPS registration points we geo-referenced the cliff mapping of Steinich (1972) to determine the spatial extent and the position of each thrust-bounded complex (Fig. 2). Considering each mapped Cretaceous complex a structurally homogeneous domain, we measured the orientations of the five fabric elements by collecting dip/dip direction data using doublecircled tectonic fabric compasses. Due to different accessibility of the Cretaceous cliff faces, the amount of data collected for each individual fabric set changes from complex to complex. However, within each complex it was possible to compute a statistical significant mean vector for each fabric element in each complex according to Wallbrecher (1986) using the STEREOMAP software by Günther (2005, Fig. 3). We assigned the resulting data (e.g., mean vectors with confidential cones and spherical apertures; Wallbrecher, 1986) to each individual structural complex for kinematical slope testing.

Serafim and Pereira (1983) formulated an empirical relationship between the score values derived from the "discontinuity condition" rating procedure, implemented in the rock mass rating (RMR) system (Bieniawski, 1989), and a residual discontinuity friction angle $\phi_{d}^{\prime}$. We used this correlation to estimate the averaged discontinuity shear strength required for the kinematical testing. In this rating procedure, the groundwater conditions of the discontinuities are an important factor reducing the frictional constraints. This is especially important for chalk rock material that significantly reduces in strength when saturated (Mortimore et al., 2004). However, as our fieldwork was conducted in a dry period, this could not be verified and thus we used conservative estimates. The obtained values from four representative rating sites are relatively homogeneous and no discrepancies between the individual discontinuity sets were observable. Therefore, we applied the integer mean of all measurements $\left(\phi_{d}{ }^{\prime}=26^{\circ}\right)$ as a global value for the kinematical rock slope testing described below. This value is in good agreement with the weak condition of the discontinuities in the Cretaceous chalk.

\subsection{Methods}

In the Cretaceous cliff portions, all types of structurally controlled failure mechanisms can be observed: plane failure, wedge failure, and toppling (e.g., Hoek and Bray, 1981; Fig. 3). For a spatially distributed kinematic rock slope analysis, we computed both the slope and the aspect from the $5 \times 5 \mathrm{~m}$ DEM on a grid cell basis using common surface derivations. We then prepared dip- and dip direction grids with the same cell size from the directional mean values of each structural fabric set for each complex, yielding the spatial extent of the outcropping rocks. Subsequently, we derived all cutting line orientations between the fabrics on a grid cell basis. These operations result in five dip- and dip direction grids for the planar fabrics, and ten plunge- and trend grids for the cutting lines. We then performed kinematical tests on a pixel basis according to the simple kinematical feasibility criteria described below for plane/wedge failure and toppling involving the global mean of $\phi_{d}{ }^{\prime}=26^{\circ}$ along all discontinuities. 


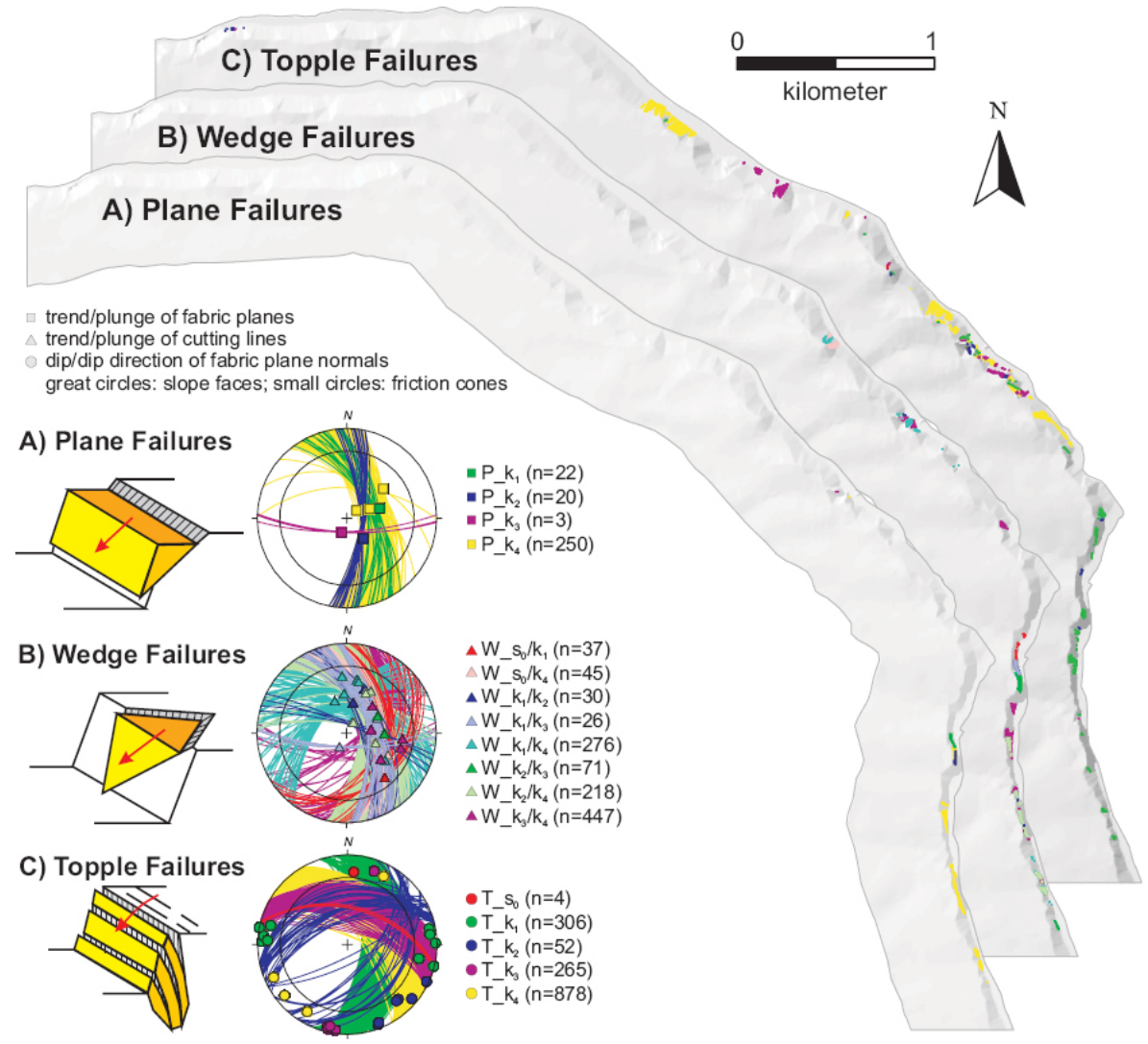

Fig. 3. Kinematical rock slope testing of Cretaceous cliff portions using mean orientation vectors of fabric sets within structural complexes, and DEM data. The evaluations were performed on a $5 \times 5 \mathrm{~m}$ pixel basis with a global residual friction angle along the discontinuities of $\phi^{\prime}=26^{\circ}$ (elucidations see text).

Conceptually, plane failures and wedge failures are kinematically feasible when the discontinuity plane or the cutting line of two discontinuities (for wedge failure) dips shallower than the slope face at cataclinal slopes, but steeper than the friction angle of the discontinuities, i.e. where

$\phi_{d}^{\prime} \leq \psi \leq \theta^{\prime}$

with $\phi_{d}^{\prime}=$ discontinuity friction angle, $\theta^{\prime}=$ apparent dip of the slope plane either in the dip direction of the discontinuity plane (for plane failure) or in the dip direction of the cutting line between two discontinuities (for wedge failure), $\psi$ dip of discontinuity/cutting line between two discontinuities (Günther, 2003). In contrast to plane and wedge failure, the assessment of topple processes are more complex. Different analytical assessment schemes exist to evaluate the kinematical feasibility of these mechanisms both on cataclinal and anaclinal slopes (e.g., Goodman and Bray, 1976; Goodman, 1980; Cruden, 1989). Following Goodman and Bray (1976), the kinematic stability criterion for toppling can be formulated as

$\theta^{\prime} \geq \phi_{d}^{\prime}+(90-\psi)$
Thereby it is assumed that toppling is not directly driven by the weight of rock columns, but rather by the stress field along the slope. The controlling discontinuity must be steep and can dip into anaclinal slopes with $\psi \leq 90^{\circ}$ (Goodman and Bray, 1976), or out of cataclinal slopes with $\psi>90^{\circ}$ (Cruden, 1989). Toppling is herein considered kinematically possible when the discontinuity reveals a steep inclination, and the strike difference between this and the slope plane at any single location (terrain pixel) is not too high. Therefore, we assume a discontinuity dip threshold of $70^{\circ}$ and a strike difference between the slope face of $10^{\circ}$ for our spatially distributed kinematic slope testing that follows the original, conservative propositions of Goodman and Bray (1976).

\subsection{Results}

The results of the GIS-based kinematical rock slope testing are displayed in Fig. 3. For each failure type (plane failure, wedge failure, topple failure; Hoek and Bray, 1981), the individual pixels are colour-coded with reference to the individual mechanisms. For simplification, pixels where more than one topple-, wedge-, or plane failure is kinematically possible are represented by only one colour in Fig. 3. In addition 
Table 1. Discontinuity-controlled failure mechanisms in Cretaceous cliff areas with individual and failure-type specific spatial extents.

\begin{tabular}{|c|c|c|c|c|c|c|c|c|c|}
\hline Failure Type & Failure mechanism & Pixels [n] & Area $\left[\mathrm{m}^{2}\right]$ & Area [\%] & Failure Type & Failure mechanism & Pixels [n] & Area $\left[\mathrm{m}^{2}\right]$ & Area [\%] \\
\hline \multirow{5}{*}{ 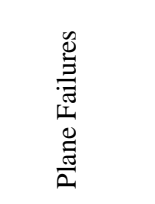 } & $\mathrm{P}_{-} k_{1}$ & 22 & 550 & 0.27 & \multirow{8}{*}{ 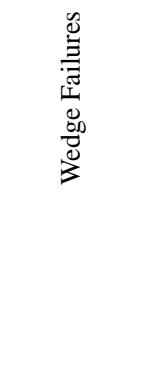 } & $\mathrm{W} \_\mathrm{s}_{0} / k_{2}$ & - & - & - \\
\hline & ${\mathrm{P} \_\mathrm{k}_{2}}_{2}$ & 20 & 500 & 0.24 & & $\mathrm{~W} \_\mathrm{s}_{0} / k_{3}$ & - & - & - \\
\hline & $\mathrm{P}_{-} \mathrm{k}_{3}$ & 3 & 75 & 0.04 & & $\mathrm{~W}_{-} \mathrm{s}_{0} / \mathrm{k}_{4}$ & 45 & 1125 & 0.55 \\
\hline & $\mathrm{P} \_k_{4}$ & 250 & 6250 & 3.03 & & $\mathrm{~W} \_k_{1} / k_{2}$ & 30 & 750 & 0.36 \\
\hline & Extent & 275 & 6875 & 3.34 & & $\mathrm{~W} \_k_{1} / k_{3}$ & 26 & 650 & 0.32 \\
\hline \multirow{4}{*}{ 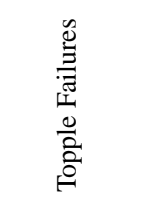 } & $\mathrm{T}_{-} \mathrm{s}_{0}$ & 4 & 100 & 0.05 & & $\mathrm{~W} \_k_{1} / k_{4}$ & 276 & 6900 & 3.35 \\
\hline & $\mathrm{T} \_k_{3}$ & 265 & 6625 & 3.22 & & $\mathrm{~W} \_k_{3} / k_{4}$ & 447 & 11175 & 5.42 \\
\hline & $\mathrm{T} \_k_{4}$ & 878 & 21950 & 10.65 & & Extent & 690 & 17250 & 8.37 \\
\hline & Extent & 1501 & 37525 & 18.21 & \multicolumn{2}{|c|}{$\underline{\text { Total extent }}$} & 2031 & 50775 & 24.65 \\
\hline
\end{tabular}

to the distribution of the possible failure locations, their corresponding geometries are plotted in equal-area projections (lower hemisphere) for each failure type. In Table 1 the twenty theoretically possible failure mechanisms and their spatial extents are listed. Seventeen of them are feasible at single pixel locations, and only two wedge failure and one plane failure mechanisms ( $\mathrm{W}_{-} \mathrm{s}_{0} / \mathrm{k}_{2}, \mathrm{~W} \_\mathrm{s}_{0} / \mathrm{k}_{3}, \mathrm{P} \_\mathrm{s}_{0}$; Table 1$)$ were not identified.

Within our study area, toppling is the most widespread failure type detected at all the three cliff sections (Fig. 3). This result is reasonable because the joint discontinuities mostly reveal a steep dip, and the cliff face dips steeper than the friction angle at most pixel locations. Toppling is therefore the most prominent failure type on pre-existent geological structures forming the Jasmund cliff. Not surprisingly, at the northeast cliff the highest potential for topple failures is along the NW-SE striking joint set $k_{4}$, followed by the WSW-ENE joint set $\left(k_{3}\right)$. Potential topple failure locations along these discontinuity sets are not detected by the algorithm along the east cliff. Kinematical feasibility of toppling along the NNE-SSW striking joint set $k_{1}$ is relatively evenly distributed at pixel clusters throughout the northeast and east cliff.

We identified possible wedge failure pixel locations at the northeast and east cliff. However, they only cover about half of the spatial extent of the topple failures (Fig. 3, Table 1). Along the northeast cliff, only one possible failure mechanism was identified for each susceptible pixel (involving $k_{3} / k_{4}, k_{1} / k_{4}$ and $\mathrm{s}_{0} / k_{4}$ bound wedges, respectively), whereas for the east cliff up to four wedge mechanisms were detected for a single pixel. Except for the $\mathrm{s}_{0} / k_{4}$ type, all wedge failure mechanisms appear at the east cliff with the $k_{3} / k_{4}$ wedge displaying the largest spatial extent (Fig. 3, Table 1). Since most of the cliff elements have to be characterised as underdip slopes or escarpments in reference to all discontinuity sets, it is evident that pixel locations with feasibility for plane failures are relatively rare (Fig. 3, Table 1). They are mostly limited to the east cliff, and the most widespread failure mechanism is the $k_{4}$ plane failure. Again, primarily one plane failure mechanism was detected in this cliff section, with the exception of a small area along "Kollicker Ufer".

The analysis reveals that $24.65 \%$ of the total outcrop area of Cretaceous rocks is susceptible to one or more failure mechanism (Table 1). This has to be considered a conservative result. However, due to the comparatively coarse resolution DEM and the application of a strictly deterministic analysis that does not involve probability distributions of fabric orientations or occurrences (e.g., Jaboyedoff et al., 2004), the outcome is sensible. Despite all its limitations, the results of the kinematical rock slope testing procedures are in good agreement with the spatial distribution of younger cliff failures and with the general stability characteristics of the Cretaceous cliff areas (see Sect. 4).

\section{Shallow landslide susceptibility zoning}

The Pleistocene glacial sediment succession is composed of till, clay and sands, whereas the undisturbed sequence consists of two tills, covered by glacial sands, and one clayey till that discordantly covers the entire deformed sequence (Panzig, 1995; Müller and Obst, 2006). However, due to intense sub-glacial tectonic deformations (Steinich, 1972) the original layering is barely preserved throughout the study area. The older glacial deposits below the unconformity (belonging to the "till/clay/sand" unit of the geological map in Fig. 1) are highly heterogeneous and reduced in thickness, sheared and incorporated into thrusting and folding. The sediments covering the deformed sequence consist of till that is at the northeast cliff overlain by a sandy unit ("till and clay" resp. "sand" units of map in Fig. 1).

Most of the landslides in the glacial sediments are of shallow translational type and usually detach at depths of 1$2 \mathrm{~m}$ along the interface with the Cretaceous rocks, or along 


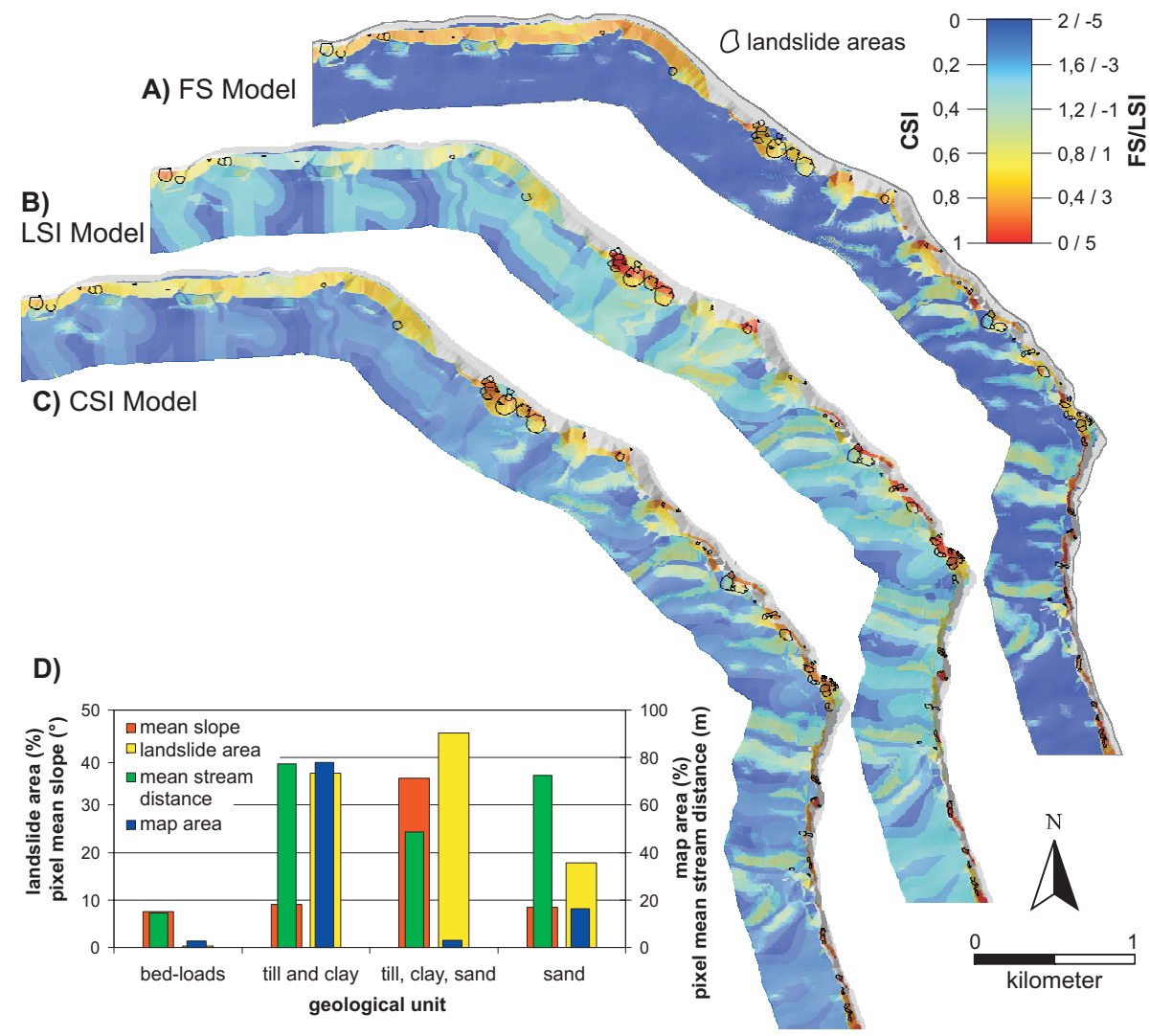

Fig. 4. Shallow landslide susceptibility models for the Pleistocene deposits. (A): physically-based factor of safety (FS) model, (B): inventorybased landslide susceptibility index (LSI) model, (C): equal-weight combination of both models (combined susceptibility index, CSI), (D): LSI model parameters in geological units (elucidations see text).

the contacts with impermeable clayey horizons. To evaluate landslide susceptibility of the Pleistocene deposits, we exploited a simple physically-based and an inventory-based model.

\subsection{Physically-based model}

The physically-based model consists of a traditional factorof-safety (FS) evaluation incorporating an infinite slope stability model combined with a steady-state hydrologic model (a topographic wetness index). For each terrain element (pixel), the slope stability factor for cohesionless material can be formulated as

$F S=\frac{\left(\gamma_{s}-w \gamma_{w}\right) D \cos ^{2} \theta \tan \phi^{\prime}}{\gamma_{S} D \sin \theta \cos \theta}$

with $\gamma_{s}=$ material unit weight $\left[\mathrm{kN} / \mathrm{m}^{3}\right], w=$ relative slope groundwater saturation $[-], \gamma_{w}=$ unit weight of water $\left[10 \mathrm{kN} / \mathrm{m}^{3}\right], D=$ thickness of material above shear plane $[\mathrm{m}]$, $\theta=$ slope angle $\left[{ }^{\circ}\right], \phi^{\prime}=$ effective material friction angle $\left[{ }^{\circ}\right]$. To determine the relative ground water saturation $w$ we used a topographic wetness index for a specific groundwater recharge rate after Montgomery and Dietrich (1994) using

$w=\frac{R a}{D k \sin \theta}$

with $R=$ recharge rate $[\mathrm{m} / \mathrm{h}], a=$ specific catchment area $\left[\mathrm{m}^{2} / \mathrm{m}\right], k=$ hydraulic conductivity $[\mathrm{m} / \mathrm{h}]$. The topographic wetness index formulated in (4) assumes a constant hydraulic conductivity throughout the transmissive layer above an impermeable shear plane, and represents a steady-state hydrologic model assuming that shallow groundwater flow follows topographic gradients (Montgomery and Dietrich, 1994; Pack et al., 1998). In our study area, the interfaces to Pleistocene till or the Cretaceous chalk are the prominent shear planes, whereas the glacial sand or sandy till are the transmissive layers. However, the application of a steadystate hydrologic model in the studied geological setting is mainly constricted because the fractured Cretaceous chalk rocks cannot be considered impermeable. Nevertheless, the permeability contrast between the chalk and the glacial sediments is very high which is documented by the fact that many shallow landslides detach near the bedrock interface (Thiel, 2007). 
Table 2. Material parameters of lithological map units used for FS modelling.

\begin{tabular}{lllllll}
\hline Unit & $\mathrm{k}_{\min }[\mathrm{m} / \mathrm{h}]$ & $\mathrm{k}_{\max }[\mathrm{m} / \mathrm{h}]$ & $\phi^{\prime}{ }_{\min }\left[{ }^{\circ}\right]$ & $\phi^{\prime}{ }_{\max }\left[^{\circ}\right]$ & $\gamma_{\max }\left[\mathrm{kN} / \mathrm{m}^{3}\right]$ & $\gamma_{\min }\left[\mathrm{kN} / \mathrm{m}^{3}\right]$ \\
\hline bed-loads & 0.00002 & 0.0001 & 28.4 & 32.7 & 18 & 16 \\
sand & 0.0286 & 0.8765 & 30.0 & 39.5 & 18 & 17 \\
till and clay & 0.00002 & 0.0286 & 28.4 & 32.7 & 20 & 17 \\
till, clay, sand & 0.001 & 0.8765 & 24.3 & 39.5 & 19 & 15 \\
\hline
\end{tabular}

We derived the values of the friction angles $\phi^{\prime}$ and the hydraulic conductivities $k$ (Table 2) empirically for each mapped sedimentary unit from particle size analysis of representative samples using derivations by Beyer (1964) for $k$ and Lang and Huder (1994) for $\phi$ ', respectively. Table 2 shows that the "till/clay/sand" unit has the highest variability in material parameters corresponding to its heterogeneous composition. The parameters values obtained for the other lithological units are comparably more homogenous. The unit weights $\gamma_{s}$ where assigned using common literature values (e.g., Dachroth 2002). To account for the spatial variability of the material parameters within the lithological map units, we computed grids with normally distributed random values between the minimum and maximum measured data shown in Table 2. The topographic wetness index grid was calculated utilizing the $\mathrm{D}_{\text {inf }}$ flow routing algorithm from Tarboton (1997) with a global groundwater recharge rate of $0.01 \mathrm{~m} / \mathrm{h}$. This recharge rate represents a pessimistic value that is assumed to correspond to a heavy rainfall event coinciding with a 100 years return period.

A very sensitive parameter for physically-based slope stability modelling is the depth of the potential shear plane, $D$ [m]. Since this value is difficult to assign in our area due to lack of data, we assumed a uniform value of $2 \mathrm{~m}$. Our pessimistic modelling neglects cohesion forces that contribute to the shear strength of the clay fractions in the glacial materials. In fact, since the materials involved are very heterogeneous and mainly composed of loose sediments, we were not able to spatially differentiate the cohesive clayey portions, and hence, we did not incorporate cohesion values.

To prepare the stability map the FS grid was filtered with a cut-off value of 2 . We applied this value because only grid cells with slope angles $<10^{\circ}$ show FS values $>2$, and no instabilities are observable in these terrains. The stability analysis thus considers only terrain with a slope angle $\geq 10^{\circ}$. Most areas at the cliff face show FS values $<1$ (Fig. 4). This is reasonable because the cliff dips steeper than the material friction angle and therefore they are unstable when applying our cohesionless modelling approach, regardless of the slope groundwater saturation. Some inbound areas show FS values $<1$, but the majority of pixels behind the cliff face have FS values $>1$ (Fig. 4A).

\subsection{Inventory-based model}

The necessary data for inventory-based landslide susceptibility modelling is the knowledge of the landslides distribution that allows the computation of functional relationships between landslide areas and spatially distributed terrain instability controlling or triggering factors (e.g., Guzzetti, 2006). All mass movements and landslide-related phenomena in the Pleistocene sediments were mapped at the 1:5000 scale by Thiel (2007) and Lange (2007). The large landslides along the northeast cliff (Fig. 1) are very old and reveal multiple younger reactivations. Most of the instabilities are classified as dormant or sub-active with some active portions. Only a few very young landslides without evidence of reactivation were mapped in the area.

As indicated by field evidence and sensitivity analysis, the most important ground conditioning parameters determining the occurrence of landslides are topographic attributes (slope angle $\theta\left[{ }^{\circ}\right]$ and the Euclidian distance to the DEM-derived stream network $v[\mathrm{~m}])$ and lithological units. Other factors like vegetation or land use are less important because they have a very uniform distribution and they do not present a strong correlation with the landslide distribution. The bivariate landslide susceptibility index (LSI) method after van Westen et al. (1993) and van Westen (1997) involves the calculation of weight for the landslide controlling parameter classes, $W_{i}$, using simple density functions:

$W_{i}=\ln \left(\frac{\rho_{c}}{\rho_{m}}\right)=\ln \left(\frac{a_{s i} / a_{n i}}{\sum a_{s i} / \sum a_{n i}}\right)$

with $\rho_{c}=$ landslide density of parameter class [-], $\rho_{m}=$ total landslide density [-], $a_{s i}=$ area containing landslides in a certain parameter class $\left[\mathrm{m}^{2}\right], a_{n i}=$ total area in a certain parameter class $\left[\mathrm{m}^{2}\right]$. To compute a compound susceptibility value for each terrain element, the separate $W_{i}$ values are simply added on a pixel basis. We classified the continuous topographic attributes, $\theta$ and $\nu$, using equal-interval slicing into eight and five classes, respectively. The geological map reveals four classes where landslides occur. The $W_{i}$ values for each parameter class were calculated using Eq. (5) and are listed in Table 3 . The resulting susceptibility map is displayed in Fig. 4B. 
A) whole model area

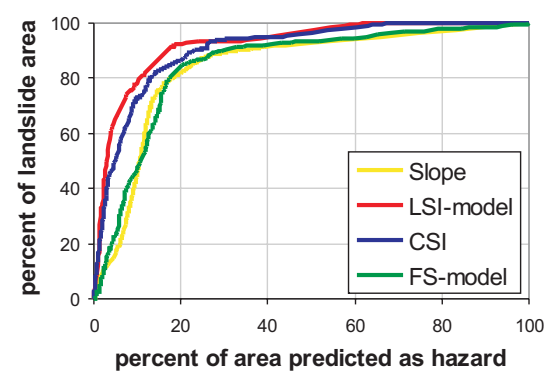

B ) reduced model area

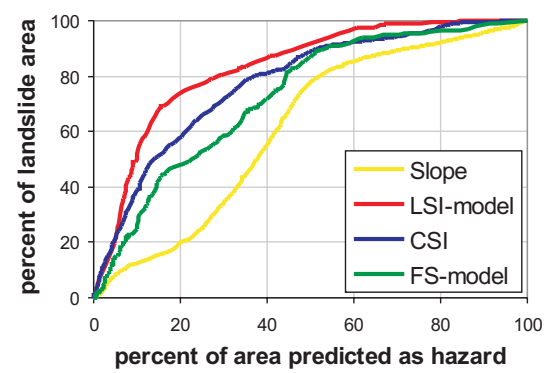

Fig. 5. Success rate evaluation of shallow landslide susceptibility models. (A): Success rate curves for the whole model area, (B): Success rate curves for a reduced model area comprising only terrain elements having a slope angle $\geq 10^{\circ}$.

Table 3. Weight values $W_{i}$ of parameter classes obtained from bivariate LSI analysis.

\begin{tabular}{|c|c|c|}
\hline Parameter & Parameter Class & $\mathrm{W}_{i}$ \\
\hline \multirow{4}{*}{ 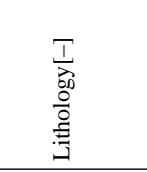 } & bed-loads & -2.27 \\
\hline & sand & 0.10 \\
\hline & till and clay & -0.83 \\
\hline & till, clay, sand & 2.65 \\
\hline \multirow{8}{*}{$\begin{array}{l}\frac{\sigma}{\bar{o}} \\
\frac{\partial}{\omega}\end{array}$} & 1: $0-9.5$ & -2.15 \\
\hline & 2: 9.5-18.9 & -0.15 \\
\hline & 3: 18.9-28.3 & 1.54 \\
\hline & 4: $28.3-37.7$ & 1.36 \\
\hline & 5: $37.7-47.1$ & 2.19 \\
\hline & $6: 47.1-56.6$ & 2.33 \\
\hline & 7: 56.6-66.0 & 1.77 \\
\hline & 8: 66.0-75.5 & 1.18 \\
\hline$\Xi$ & 1: $0-62$ & 0.42 \\
\hline है & 2: $62-123$ & -0.70 \\
\hline 巳一๊ & 3: $123-185$ & -1.18 \\
\hline$\cong$ & 4: 185-247 & -2.58 \\
\hline$\dot{\vec{\omega}}$ & 5: $247-308$ & -2.95 \\
\hline
\end{tabular}

The most landslide-prone lithological class is the "till/clay/sand" unit cropping out at the cliff face (Table 3), followed by the "sand" unit present at the northeast cliff (Fig. 1). Slope classes 5 and 6 (Table 3) bear the highest $W_{i}$ values for the terrain slope. The weight values of the "distance-to-streams" classes are approximately linearly decreasing, suggesting that shallow landslide distribution is highly controlled by the height of the groundwater table (the stream network is shown in Fig. 1). The LSI susceptibility map presents values ranging between -5.407 and 5.398. For visual purposes, the map was filtered to the nearest integers of these values (Fig. 4B).

Like any bivariate analysis our inventory-based susceptibility model assumes conditional independence of the input parameters. In our study area, a strong correlation between the lithological class "till/clay/sand" and the slope gradient can be observed (Fig. 4D). This unit covering only $3 \%$ of the area contains $45 \%$ of the landslide area. The mean slope angle of the other lithological units are relatively similar, the negative $W_{i}$ value for the "bed-loads" results from the fact that this unit nearly contains no landslide areas (Fig. 4D). The "sand" unit covering large flat areas has a considerable portion of landslide area even though it only covers $18 \%$ of the investigated area, which is mainly the reason why this unit has a positive $W_{i}$ value (Fig. 4D, Table 3). On the other hand, "till and clay" covers $78 \%$ percent of the study area but has a low landslide density even though this parameter class is present at the steep north cliff face.

\subsection{Evaluation and integration of the models}

When comparing qualitatively the two susceptibility maps prepared with the FS model (Fig. 4A) and the LSI model (Fig. 4B), they show a relatively good agreement. In the gently sloping terrain inbound of the north and northeast cliff only the LSI model provides a susceptibility estimate, because we did not apply the FS model for pixels having a slope angle $<10^{\circ}$ (see Sect. 3.1). In Fig. 4, the spatial agreement of the two models can be observed to be highest along the east cliff portion. In the vicinity of the northeast cliff the landslide distribution north of "Stubbenkammer" and at "Kollicker Ort" (Fig. 1) are better predicted by the inventorybased LSI model than by the FS model.

The most conspicuous discrepancy between the two models exists for the north cliff. Here, the FS susceptibility model exhibits a more pessimistic pattern (more pixel values indicate unstable conditions, i.e. $\mathrm{FS}<1$ ) than the LSI model (Fig. 4). In this part the cliff mainly dips steeper than the friction angle of the Pleistocene deposits, whereas the landslide density is comparably low. Many terrain elements along the north cliff are unstable and some geomorphologic evidence highlight active slope creeping along different slope sections (Thiel, 2007). In fact, discrete landslide failures are scarce, because the north cliff is stabilized by the well-developed 
cliff toe consisting of relatively wide beach deposits. Thus, both modelling results can be considered valid: the landslide density along the north cliff is low, and in such the susceptibility level displayed by the inventory-based LSI model. However, these slopes are potentially unstable and if invasive slope re-designing works are undertaken, catastrophic landslides could occur (Fig. 1). Therefore, slopes of the north cliff bear high potential landslide susceptibility even though this is overestimated by the FS model and partially underestimated by the inventory-based LSI model.

The success-rate curves prepared for the LSI and the FS susceptibility models (Chung and Fabbri, 2003) indicate a good performance of both the LSI and the FS models (Fig. 5). However, in our study area the majority of the landslides are situated along the steep cliff face, and most of the inbound area is flat. Since the slope angle is the main factor controlling the instabilities, the success rate curves can be expected to show a good performance. This is evidenced by the success rate curve that results from using a reclassification of the topographic slope grid as the only predictor (Fig. 5A). To investigate the significance of the models more in detail, we calculated the success rates of both models only for terrain elements with slope angles $\geq 10^{\circ}$ (Fig. 5B). In these areas, the slope gradient has a comparably poor significance, but both the FS and LSI models show better success rates. As indicated in Fig. 5, the success rate of the LSI model is higher than of the FS model in both cases. This can be explained by the fact that the LSI model is based on the inventory data it is evaluated with, whereas the FS model does not use this information to prepare the susceptibility estimate.

To display the inventory- and the physically-based analysis in a single map and to produce an integrated susceptibility map for the shallow landslides, we attempted to aggregate the results of the two models in a single layout. For this purpose, the LSI and the FS models were normalized by linear rescaling. Then, for each pixel we calculated the mean value overlaying the two models. Because the FS model ranges from 0 to 2 ( $F S=1$ is the stability threshold), and the LSI model ranges from -5 to 5 , a linear rescaling is appropriate. Figure $4 \mathrm{C}$ displays the spatial distribution of the combined susceptibility index (CSI). Figure 5 shows an increase in the CSI model performance comparing to the FS model.

For the evaluation of the shallow landslide susceptibility of the glacial deposits we prefer the CSI map more than the FS and LSI models for the following reasons: (i) the map comprises a combination of a stability ratio and a susceptibility index and hence relies on both (simple) physical and empirical principles; (ii) the map reduces the general oversimplification of simple static infinite slope based models; (iii) the map abates the problems of empirical assessments based on landslide inventory incorporating stability criteria and therefore better predicting future landslide occurrences.

\section{Combined failure susceptibility map}

We prepared a combined failure susceptibility map merging the landslide susceptibility map (CSI) for the Pleistocene deposits with the kinematical evaluations of the Cretaceous chalk (Fig. 6). For this purpose, we added the results of the kinematical rock slope testing (Sect. 2) to determine the number of kinematically feasible failure mechanisms for each pixel. The resulting integer grid (yielding values from 0 to 6 ) can be interpreted as a rock slope failure susceptibility map, assuming that terrain elements with higher values are more susceptible for cliff failures than those with lower counts. We then reclassified the grid into four classes rendering low, moderate, high and very high failure susceptibility (Fig. 6). Due to the limitations of the DEM and the deterministic basis of the kinematical analysis (see Sect. 2), we classified terrain elements without failure mechanisms as low susceptible. We then reclassified the shallow landslide susceptibility map (Sect. 3) into four susceptibility classes using equal interval slicing (Fig. 6). In a last step we spatially merged the reclassified the susceptibility map for the Cretaceous rocks with the reclassified susceptibility map prepared for the Pleistocene glacial deposits (Fig. 6).

The suitability of the rock slope failure susceptibility classification as part of the combined landslide susceptibility map is shown by the good agreement with the locations of recent large-volume Cretaceous cliff collapses (Fig. 6); 67\% of the failures are positioned in the highest susceptibility class. However since only six recent cliff collapses are available to validate the analysis, the results are preliminary. The model predicts large areas of the east cliff (mostly located at "Kollicker Ufer" and "Kieler Ufer", Fig. 1) to be highly prone to complex, larger scale rapid cliff failures. This is also underlined by the concave nature of the east cliff, indicating its high activity. In contrast, the northeast cliff in general shows a lower susceptibility to rock slope failures, and only some small areas at "Stubbenkammer" are classified as highly susceptible. Field observations and historical data support these results. Cliff retreat along the northeast cliff can be considered a continuous process involving small scale, low volume cliff erosion, whether along the east cliff this is more attributed to catastrophic large-volume failures.

The model success rate of the integrated shallow landslide susceptibility zoning has already been discussed in Sect. 3.3. The classification used to define the four susceptibility levels (Fig. 6) is robust since $>80 \%$ of the mapped landslides are located within the two highest susceptibility classes, and only less than $4 \%$ are situated in the lowest susceptibility class. Terrain that pertains to the very high susceptibility class is present only along the cliff face. However along the northeast cliff, sections with high susceptibility values are also present inbound the cliff within Pleistocene sediments. Most of the gentle sloping terrain behind the cliff face belongs to the low landslide susceptibility class with some areas along the flanks of river channels attributed to moderate levels. 


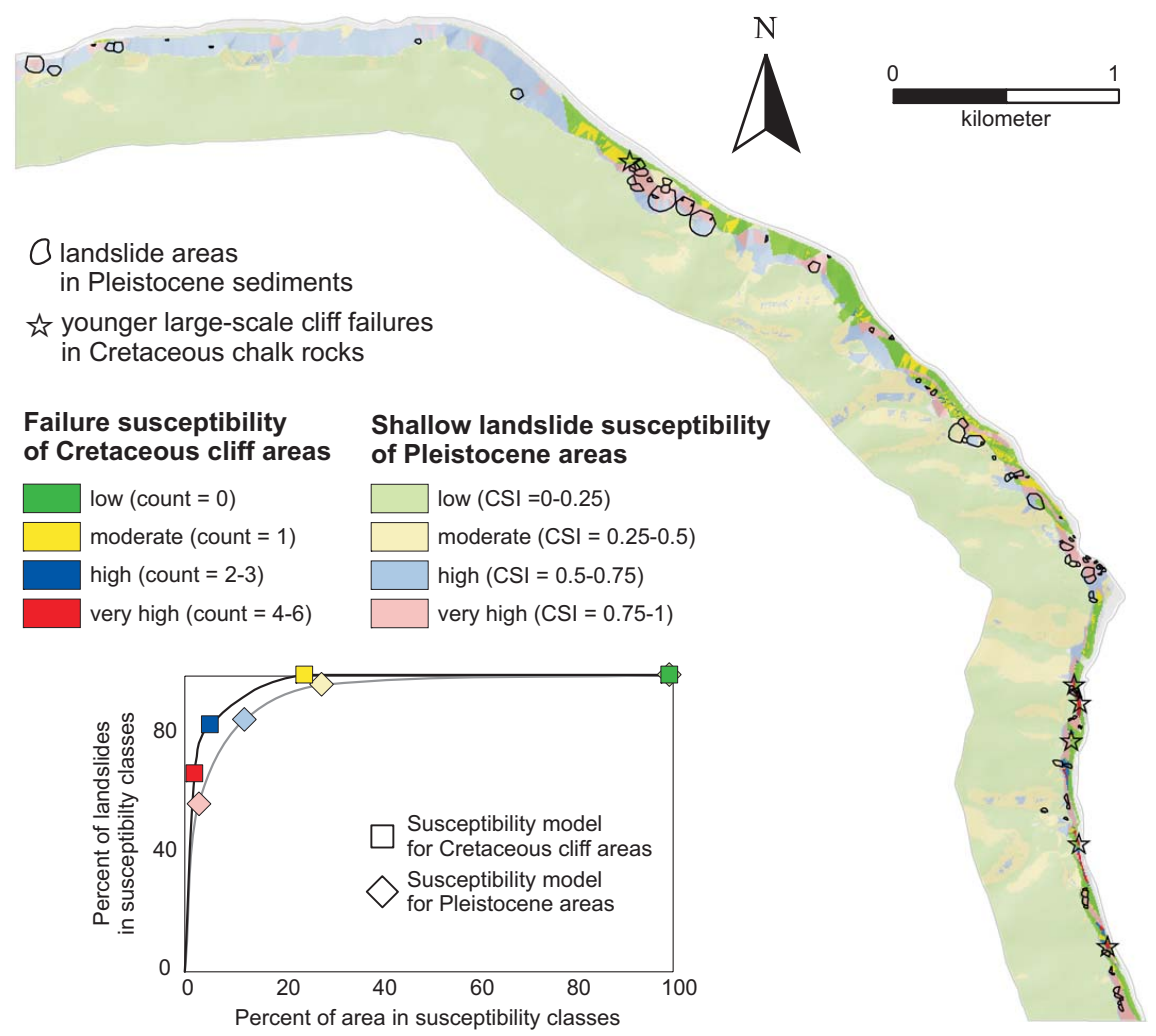

Fig. 6. Combined landslide susceptibility map displaying structurally controlled failure susceptibility of Cretaceous cliff portions, and shallow landslide susceptibility of Pleistocene glacial deposits.

\section{Conclusions}

We have presented an approach to evaluate both the structurally-controlled rock slope failure susceptibility, and the topographically-controlled shallow landslide susceptibility along the complex geological cliff of Jasmund (Rügen Island, Germany). We evaluated the failure susceptibility of the cliff portions consisting of Cretaceous chalk rocks using a kinematical rock slope testing procedure for all structurallycontrolled failure mechanisms. With this data, we derived a susceptibility map by integrating the failure counts for each terrain element $(5 \times 5 \mathrm{~m}$ pixel $)$. We analyzed the shallow landslide susceptibility of the Pleistocene glacial deposits exploiting a physically-based and an inventory-based procedure, and we averaged the two models to obtain a combined susceptibility estimate. We classified the susceptibility maps prepared for the Pleistocene deposits and for the Cretaceous cliffs into four susceptibility levels and we spatially merged them to derive an integrated susceptibility map.

To improve the rock slope failure assessments, higher resolution DEMs are the major prerequisite. The susceptibility map presented in this paper was used to identify areas for multi-temporal, high resolution LIDAR scanning surveys. Results of the first campaign of these airborne helicopter sur- veys indicate that slope kinematics of critical sections can be analyzed in more detail using the spatially distributed structural fabric data. Multi-temporal LIDAR data combined with the structural models can provide valuable information for future investigation of slope dynamics. In terms of scenariobased rock slope stability analysis, the groundwater flow regime of the Cretaceous rocks has to be known and modelled. Attempts to quantify the in- and outflow magnitudes, required to characterize the retention potential within the rock slopes, are currently undertaken. Based on hydrological and structural data, it will be possible to establish a simple hydraulic model for the Cretaceous rock slopes that can be used for spatially distributed stability calculations. Furthermore it would be of great benefit to extend the deterministic rock slope analysis presented herein utilizing probabilistic assessment schemes in order to evaluate rock discontinuity occurrences, orientations, and properties (e.g., Jaboyedoff et al, 2004; Park et al., 2005). This is of particular interest for problems at larger spatial scales with the high resolution DEM discussed above. More data on rock mass- and discontinuity properties should to be collected to obtain their probability distributions.

The physically-based shallow landslide susceptibility zoning could be improved by spatially implementing the 
information on the thickness of the Pleistocene deposits. Moreover, it is crucial to differentiate the glacial sediments in more detail through large-scale mapping and sampling in order to obtain better material strength data (including cohesion values for clayey materials). To overcome the limitations of the simple steady-state hydrologic model, the integration of a more realistic transient modelling scheme that accounts for groundwater infiltration (e.g., Iverson, 2000) could be mandatory. Information on hydraulic conductivities and diffusivity, data on groundwater retention and -recharge, and local precipitation data are needed to parameterize such models which could be used to compute shallow landslide initiation scenarios due to different triggering (precipitation) events (e.g., Godt et al., 2008). For improvement and validation of the inventory-based modelling approaches, multitemporal landslide inventories are of major importance.

Despite all its limitations, the combined landslide susceptibility map including both rock slope failures in Cretaceous rocks and shallow landslides in Pleistocene deposits is able to resemble the locations of past and present mass movements. Therefore the results are valuable to predict the locations of future failures. If it will be possible to improve the models as described above, scenario-based spatial landslide hazard evaluations for both rock slope and shallow landslides will be possible. The methodology presented can be applied in similar geological situations for the evaluation of landside induced failures along cliffs composed by rock slope and soft sediment terrains. It is important to highlight that the resolution of the available DEM assigns the resolution of any structural models for kinematical slope testing. Furthermore, the amount and quality of available input data used for the topographically-controlled landslide susceptibility assessments determines the choice of the modelling approach.

Acknowledgements. We like to thank Christin Lange (University of Greifswald, Germany), Dirk Kuhn and Dirk Balzer (BGR Hannover, Germany), Karsten Schütze and Karsten Obst (Landesamt für Umwelt, Naturschutz und Geologie, Güstrow, Germany), and Michael Weigelt (National Park Jasmund, Rügen, Germany) for their collaboration during field work, data acquisition, and many fruitful discussions. We are indebted to Lars Tiepolt (Staatliches Amt für Umwelt und Natur, Rostock, Germany) for providing the DEM data. We are grateful to the journal reviewers and the editor for their constructive reviews of the manuscript.

Edited by: P. Reichenbach

Reviewed by: P. Frattini, G. Stock and one anonymous referee

\section{References}

Beyer, W.: Zur Bestimmung der Wasserdurchlässigkeit von Kiesen und Sanden aus der Kornverteilung, Wasserwirtschaft, Wassertechnik, Berlin, 1964 (in German).

Bieniawski, Z. T.: Engineering rock mass classifications, Wiley, New York, 251 pp., 1989.
Chung, C.-J. F. and Fabbri, A. G.: Validation of spatial prediction models for landslide hazard mapping, Nat. Hazards, 30, 451472, 2003.

Cruden, D. M.: Limits to common toppling, Can. Geotech. J., 26, 737-742, 1989.

Dachroth, W.: Handbuch der Baugeologie und Geotechnik , Springer, Berlin, 2002 (in German).

Duperret, A., Genter, A., Martinez, A., and Mortimore, R. N.: Coastal chalk cliff instability in NW France: role of lithology, fracture patter and rainfall, in: Coastal chalk cliff instability, edited by: Mortimore, R. N. and Duperret, A., Geological Society, London, Engineering Geology Special Publication, 20, 8997, 2004.

Godt, J. W., Baum, R. L., Savage, W. Z., Salciarini, D., Schulz, W. H., and Harp, E. L.: Transient deterministic shallow landslide modeling: Requirements for susceptibility and hazard assessment in a GIS framework, Eng. Geol., 102, 214-226, 2008.

Goodman, R. E.: Introduction to Rock Mechanics, Wiley, New York, 562 pp., 1980.

Goodman, R. E. and Bray, J. W.: Toppling of rock slopes, Proc. Speciality Conference on Rock Engineering for Foundations and Slopes, American Society of Civil Engineers (ASCE), Boulder CO, 201-234, 1976.

Günther, A.: SLOPEMAP: programs for automated mapping of geometrical and kinematical properties of hard rock hill slopes, Computers and Geosciences, 29, 865-875, 2003.

Günther, A.: STEREOMAP - Orientation data analysis in ArcView GIS, program code, http://arcscripts.esri.com/details.asp?dbid= 14073 (last access: 29 April 2009), 2005.

Günther, A., Carstensen, A., and Pohl, W.: Automated sliding susceptibility mapping of rock slopes, Nat. Hazards Earth Syst. Sci., 4, 95-102, 2004,

http://www.nat-hazards-earth-syst-sci.net/4/95/2004/.

Guzzetti, F.: Landslide hazard and risk assessment, $\mathrm{Ph}$. D. Thesis, Rheinische Friedrich-Wilhelm-Universität Bonn, http://hss.ulb.uni-bonn.de/diss_online/math_nat_fak/2006/ guzzetti_fausto/index.htm (last access: 29 April 2009), 2006.

Hoek, E. and Bray, J. W.: Rock Slope Engineering, The Institution of Mining and Metallurgy, London, 358 pp., 1981.

Hutchinson, J. N.: Chalk flows from the coastal cliffs of northwest Europe, In: Evans, S. G. and DeGraff, J. V. (Eds): Catastrophic landslides: effects, occurrence, and mechanisms, Rev. Eng. Geol., 15, 257-302, 2002.

Iverson, R. M.: Landslide triggering by rain infiltration, Water Resour. Res., 36, 1897-1910, 2000.

Jaboyedoff, M., Baillifard, F., Philippossian, F., and Rouiller, J.-D.: Assessing fracture occurrence using "weighted fracturing density": a step towards estimating rock instability hazard, Nat. Hazards Earth Syst. Sci., 4, 83-93, 2004, http://www.nat-hazards-earth-syst-sci.net/4/83/2004/.

Lang, H.-J. and Huder, J.: Bodenmechanik und Grundbau: Das Verhalten von Böden und die wichtigsten grundbaulichen Konzepte, Springer, Berlin, 1994 (in German).

Lange, C.: Geologisch-geomorphologische Analyse der historischen und rezenten Abbrüche an der Küste Jasmunds/Rügen , Diploma-thesis, University of Greifswald, unpublished, 2007 (in German, with English abstract).

Montgomery, D. R. and Dietrich, W. E.: A physically based model for the topographic control on shallow landsliding, Water Resour. 
Res., 30, 1153-1171, 1994.

Mortimore, R. N., Stone, K. J., Lawrence, J., and Duperret, A.: Chalk physical properties and cliff instability, in: Coastal chalk cliff instability, edited by: Mortimore, R. N. and Duperret, A., Geological Society, London, Eng. Geol. Special Publication, 20, 89-97, 2004.

Müller, U. and Obst, K.: Lithostratigraphie und Lagerungsverhältnisse der pleistozänen Schichten im Gebiet von Lohme (Jasmund/Rügen), Zeitschrift für geologische Wissenschaften, 34, 39-54, 2006 (in German, with English abstract).

Obst, K. and Schütze, K.: Ursachenanalyse der Abbrüche an der Steilküste von Jasmund/Rügen, Zeitschrift für geologische Wissenschaften, 34, 11-37, 2006 (in German, with English abstract).

Pack, R. T., Tarboton, D. G., and Goodwin, C. N.: The SINMAP approach to terrain stability mapping, Proc. 8. Congress IAEG, Vancouver, 1998.

Panzig, W.-A.: Zum Pleistozän Nordost-Rügens, Terra Nostra, 6, 177-200, 1995 (in German).

Park, H.-J., West, T. R., and Woo, I.: Probabilistic analysis of rock slope stability and random properties of discontinuity parameters, Interstate Highway 40, Western North Carolina, USA, Eng. Geol., 79, 230-250, 2005.

Serafim, J. L. and Pereira, J. P.: Considerations on the geomechanical classification of Bieniawski, Proc. International Symposium for Engineering Geology and Underground Construction, 33-43, Balkema, Rotterdam, 1983.
Steinich, G.: Endogene Tektonik in den Unter-MaastrichtVorkommen auf Jasmund/Rügen, Geologie, 21-22, 1-207, 1972 (in German).

Tarboton, D. G.: A new method for the determination of flow directions and upslope areas in grid digital elevation models, Water Resour. Res., 33, 309-319, 1997.

Thiel, C.: Vergleichende flächenhafte Modellierung von Rutschungsempfindlichkeiten der Pleistozänen Sedimente an der Steilküste Jasmunds/Rügen, Diploma-thesis, University of Tübingen, unpublished, 2007 (in German, with English abstract).

van Westen, C. J.: Statistical landslide hazards analysis, ILWIS 2.1 for Windows application guide, ITC Publication, http://www. itc.nl/ilwis/Applications/application05.asp (last access: 29 April 2009), 1997.

van Westen, C. J., van Duren, I., Kruse, H. G. M., and Terlien, M. T. J.: GISSIZ: training package for geographic information systems in slope instability zonation, ITC Publications, 15, ITC Enschede, 1993.

Wallbrecher, E.: Tektonische und Gefügekundliche Arbeitsweisen, Enke-Verlag, Stuttgart, 1986 (in German).

Williams, R. B. G., Robinson, D. A., Dornbusch, U., Foote, Y. L. M., Moses, C. A., and Saddleton, P. R.: A Sturzstrom-like cliff fall on the chalk coast of Sussex, UK, in: Coastal chalk cliff instability, edited by: Mortimore, R. N. and Duperret, A., Geological Society, London, Engineering Geology Special Publication, 20, 89-97, 2004. 